\title{
An Association Study of Energy and Substance Transformations in Ripening Process of Banana Damaged by Loading Force *
}

\author{
Fengying Xu, Zhen Chen, Pengcheng Wang, Changyou Li, Ce Xu, Yongfeng Chen, Xingbin \\ Luo
}
Key Laboratory of Key Technology on Agricultural Machine and Equipment, (South China Agricultural University), Ministry of Education, Guangzhou 510642, P.R. China

\begin{abstract}
Researches on the relation of a loaded mechanical energy to the damaged banana maturation and its quality evolution has significance to its storage, but there are few researches at present. This paper studied on the effect of the loaded energy on banana to its internal maturation substance evolution and stored quality with time, including the change of maximum impact stress, re-enduring impact energy. The results showed there existed a significant correlation between energy transformation and increment of maturity substance in the damaged banana. Also, there existed a significant association between energy transformation and increment of maturity substance in the damaged banana in its storage time, and appeared a trends that the mechanical energy being transferred into fruit internal energy increased its maturity substance and decreased its stored quality, but individual maturity difference had less effect. Thus, decreasing the energy and the substance transformation in damage area are the important means of extending the physiology life of fruits, which is an urgent problem to be solved in their field of processing and storage at present.
\end{abstract}

Index Terms: Ethylene release rate; energy and substance transformation; damage; association; ripening banana.

(C) 2012 Published by MECS Publisher. Selection and/or peer review under responsibility of the Research Association of Modern Education and Computer Science.

\section{Introduction}

For the substance $\mathrm{C}_{2} \mathrm{H}_{4}$ could ripen the fruit and external loads could deepen the biological invasion, the bananas quality in storage was susceptible to the effects of external loads and ripening substances of ethylene $\mathrm{C}_{2} \mathrm{H}_{4}$ etc. [1-3]. At present, many researches focused on the physiological and biochemical mechanism of

\footnotetext{
* This work is supported by NSFC Grant \#31071583 to F.Y.Xu and Guangdong Provincial NSFC Grant \#9251064201000009.

* Corresponding author.

E-mail address: xu fy@scau.edu.cn
} 
banana's appearance quality, which have analyzed its effect on the processes of color change that caused by enzymatic browning of its mature cells [4-5], some researches have conducted on physiological changes and regulating of maturation substance ethylene $\mathrm{C}_{2} \mathrm{H}_{4}$, the evolution process of banana appearance quality also have been macroscopically investigated by experiments [6-8]. The above researches tend to reveal banana physiological quality change process from internal biochemical reactions, which are lack of the intensity of energy transformation effect associated with the biochemical process of maturation substance [9-12], thus they have a limited guidance to the systematical reduction of the losses during banana storage. To better maintain the banana quality $[5,9,12]$ for the development of processing and storage equipment, in this paper, an experimental research on the macroevolution mechanism of the substance and energy transformation in ripening process of the damaged banana was launched.

\section{Experimental Materials, Instrument and Equipment}

\subsection{Selection of Materials}

In the experiments, a batch of mature local bananas with uniform size, freshness and no damage were selected, which were stored after sterilization. A total of 148 bananas were tested in three groups as following, respectively.

(1) To analyze the maximum endurable mechanical energy of non-damage banana in every-day storage, 54 bananas were divided into three samples from 0 to 2 day.

(2) To measure the maximum re-enduring mechanical energy and its damage intensity at the back of the damaged banana, there were 48 bananas were be checked. The measuring reference of $3 \mathrm{~mm}$ distance from of fruit stalk was adopted, from which 3 positions were evenly measured.

(3) 36 loaded damaged bananas was used to measure the intensity of substance transformation, which were divided into four samples of $0 \mathrm{~N}, 20 \mathrm{~N}, 40 \mathrm{~N}$ and $60 \mathrm{~N}$, whose the respiration rate of ethylene $\mathrm{C}_{2} \mathrm{H}_{4}$ from the substance transformation product were determined. 3 bananas were set in each sample, and sealed in a tank for $2 \mathrm{H}$ before the injection; the sampling injection volume of gas was $1 \mathrm{~mL}$. In each loading force, three times repeated sampling were done, and after completing the determination, bananas were horizontally laid to store in a basket.

\subsection{Experimental Instrument and Equipment}

In the experiments, the mechanical energy from the first external loading force on banana were applied by the WD-20KE precision electronic universal mechanical testing machine, which was manufactured by Grandtry Testing Instruments Co., Ltd., the measuring range was $0.20-20 \mathrm{KN}$ and the testing speed range was 0 $500 \mathrm{~mm} / \mathrm{min}$, the loading indenter diameter of $\Phi 15 \mathrm{~mm}$ was selected and the testing speed of $0.1 \mathrm{~N} / \mathrm{s}$ was used. GC-3900 gas chromatograph produced by Hitachi was used in the determination of respiratory rate, the chromatographic conditions were as follows: CTR 1 column, column temperature at $50^{\circ} \mathrm{C}$, sampling chamber temperature at $150{ }^{\circ} \mathrm{C}$, He as carrier gas, flow rate $30 \mathrm{~mL} \cdot \mathrm{min}^{-1}$, thermal conductivity detector (TCD) temperature at $150{ }^{\circ} \mathrm{C}$.

The maximum re-enduring mechanical energy and its damage strengths of banana were determined by the fruits and vegetables' hardness tester Instron5542, which was manufactured by the U.S. Instron Corporation, and the indenter diameter was $\Phi 8 \mathrm{~mm}$ and the precision was $0.1 \mathrm{MPa}$. Banana volume was determined by drainage, and JJ-1000 electronic balance of the G \& G CO., LTD was used to measure it mass. 


\subsection{Calculation of The Mechanical power and The Ethylene Release Rate}

The calculation formula of the loading mechanical power was:

$$
E=\frac{1}{2} F_{\max } S_{\max }
$$

Where $E$ was the loading power, $F_{\max }$ was the maximum loading force, and $S_{\max }$ was the maximum loading deformation.

The respiration rate of ethylene from transformation productions of loaded and damage banana was calculated by (2):

$$
R R\left(\mu L \cdot h^{-1} \cdot k g^{-1}\right)==\frac{C \cdot V}{H \cdot W}
$$

Where $R R$ was the ethylene release rate, $C$ was the ethylene concentration, $V$ was the volume difference of container and fruit(uL), $H$ was the sealing time(h), $W$ was the mass of the sampling fruit(kg)

\section{Experimental results}

After the bananas in above Selection of Materials (1) to (3) were experimentally determined respectively, the first loading mechanical energy associated with the change of the ethylene release rate were investigated with Microsoft Excel2000 and Matlab software, where the experiment data were analysed and plotted statistically with their mean and standard error. Fig. 1 showed the relation of bananas first loading force and its endurable mechanical energy in different storage time.

It could be seen that with the extension the storage days of the damaged banana, the endurable mechanical energy and its fluctuation slightly increased under the same external forces, especially for the loads of $40 \mathrm{~N}$ at the day 1 and $60 \mathrm{~N}$ at the day 2, the fluctuations amplitude were the most significant. When the loading force was smaller and more than $20 \mathrm{~N}$, the endurable mechanical energy of banana affected by first load rapidly increased, and the fluctuations amplitude increased. When the loading force further increased to $60 \mathrm{~N}$, at the day 2 , the mechanical energy of banana enduring weakened. It could be that the release of ethylene etc. substance promoted the expansion and maturity of individual cells, intensified the structural strength of individual, and speeded the increase of its endurable mechanical energy when the bananas were first loaded, but there exist individuals uneven maturity, so at later stage the fluctuation amplitude of the deviation were larger.

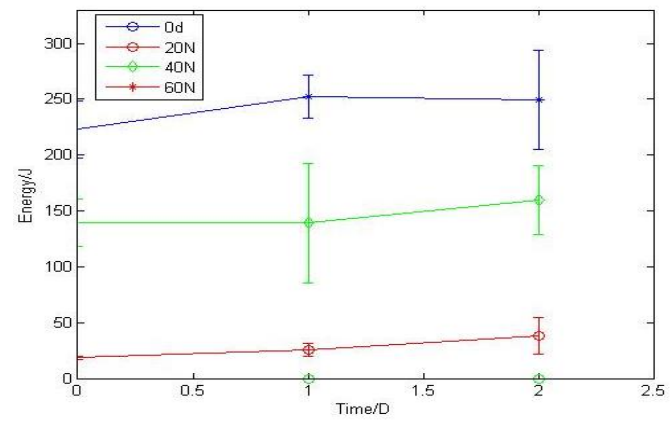

Fig. 1. Relation of bananas first loading force and its endurable mechanical energy in storage. 
Fig. 2 showed the change relation of damaged banana maximum re-enduring mechanical energy and time, which could be seen that with the increases of storage time, its energy occurred a slight amplitude downtrend. While the damaged individuals were loading forces at $20 \mathrm{~N}$ and $60 \mathrm{~N}$, it was basically consistent with the change of time, and presented as the change trends in turn. The changes of the undamaged banana and the damaged banana by loading $40 \mathrm{~N}$ were relatively close, except that the re-enduring mechanical energy at the day 1 slightly increased, and the change trends of the rest were consistent. It basically showed that if the loading force was bigger, the re-enduring energy was smaller. The fluctuation amplitude of the re-enduring mechanical energy after loading intensified, which indicated that the ripening of banana loaded by force could be not only associated with the maturity difference of the individual, meanwhile, the enlargement of the loading force increased the damage, and the increase of the transformed chemical energy accelerated the ethylene generation of banana maturity substance, the biochemical process in banana accelerated the decrease of its quality, the damage resistance capacity of banana individuals re-enduring mechanical energy further weakened.

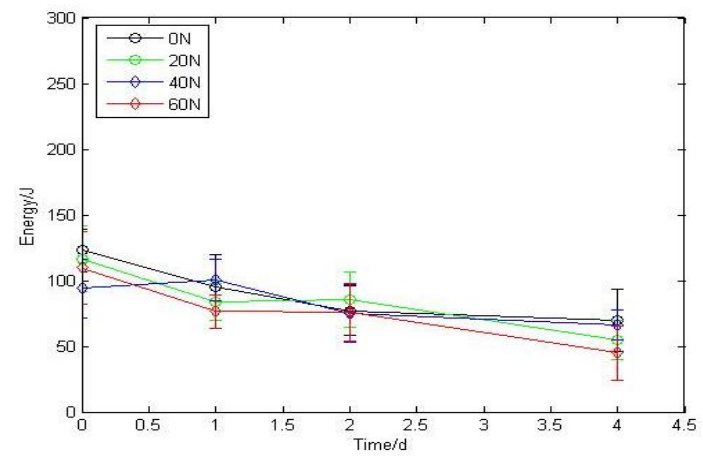

Fig. 2. Change relation of maximum re-enduring mechanical energy and time.

Fig.3 showed the change relation of the damaged banana re-enduring tress in storage. It could be seen that with the increase of re-enduring loading forces, except that the maximum stress of the damaged bananas at the day 1 appeared the small amplitude fluctuations, the other in different storage time occurred a small amplitude downtrend, the maximum stress of the bananas at the day 0 , day 2 and day 4 of presented the overall decline, while the maximum stress of the bananas at the day 0 endured the loading force of $60 \mathrm{~N}$, the enduring stress slightly increased and the hardness of damage banana at the day1 was larger than that of the three former. The re-enduring loading forces increased, then the fluctuation range of maximum re-enduring stress as same changed, while the force was $40 \mathrm{~N}$ and $60 \mathrm{~N}$, the fluctuation ranges of banana individual's stress were bigger, the maximum stress of banana re-enduring at the day 1 increased, then significantly reduced in turn. The reason could be that the bananas were first loaded by force with the enlargement of the forces, the amount of input mechanical energy transformed into chemical energy increased, but its internal maturity substance $\mathrm{C}_{2} \mathrm{H}_{4}$ releases rate was less, the overall cells were further expanded, while in the corresponding damaged region the ulceration and spoilage of banana cells were minor, its overall intensity was improved. With the extension of storage time, the ethylene etc. maturity and ripening substance in damage banana further released, the physiological and biochemical process of the inflated cell bodies of banana were accelerated, so, the capacity of banana resistance to germs invasion weakened, and the maximum failure stress of banana re-enduring was reduced. 


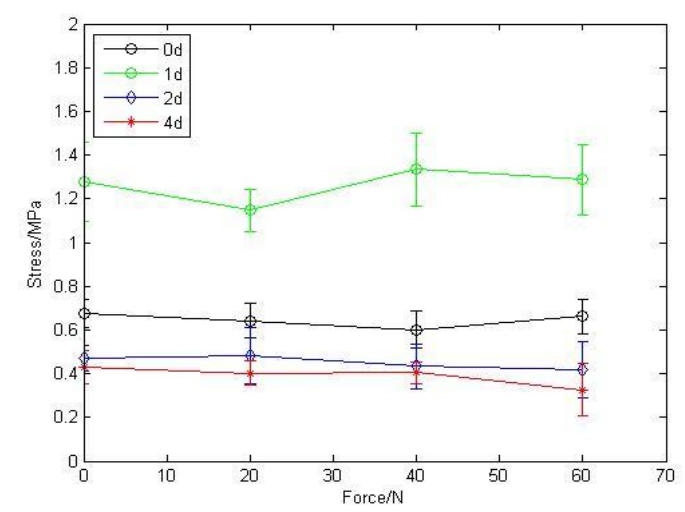

Fig. 3. Change relation of the damaged banana re-enduring force with its tress in storage.

Figure 4 showed the relation of the damaged bananas ethylene release rate with first enduring mechanical energy, which could be seen that with the increase of loading energy, the ethylene $\mathrm{C}_{2} \mathrm{H}_{4}$ release rate of damage banana in different storage time generally increased with the enlargement of first loading mechanical energy, then there were fluctuations. At the day 1 and the day 3, when the loading mechanical energy was 223J, the release rate of ethylene $\mathrm{C}_{2} \mathrm{H}_{4}$ decreased lightly, on the condition of slight load, except for day 2 and day 4, the release rate of damage banana's ethylene $\mathrm{C}_{2} \mathrm{H}_{4}$ had the slight increases compared with initial normal state. With the increase of the storage time, except that the ethylene release rate at $18 \mathrm{~J}$ and $139 \mathrm{~J}$ of the day 4 slightly lowered than that of the day 3 , the ethylene $\mathrm{C}_{2} \mathrm{H}_{4}$ release rates increased in overall performance. The reason may be that the input energy for loading increased the amount of mechanical energy transformed into chemical energy for the damaging banana, and the increased chemical energy promoted the biochemical enzymatic reaction of inner material, then the ethylene $\mathrm{C}_{2} \mathrm{H}_{4}$ release concentration was increasing. With the increase of storage days, undamaged cells were gradually ageing, the continuous release of ethylene may decrease, because of the individual maturity difference, ethylene $\mathrm{C}_{2} \mathrm{H}_{4}$ release rate reached the peak value may appear the asynchrony, made the quality change appear some fluctuations in the trend.

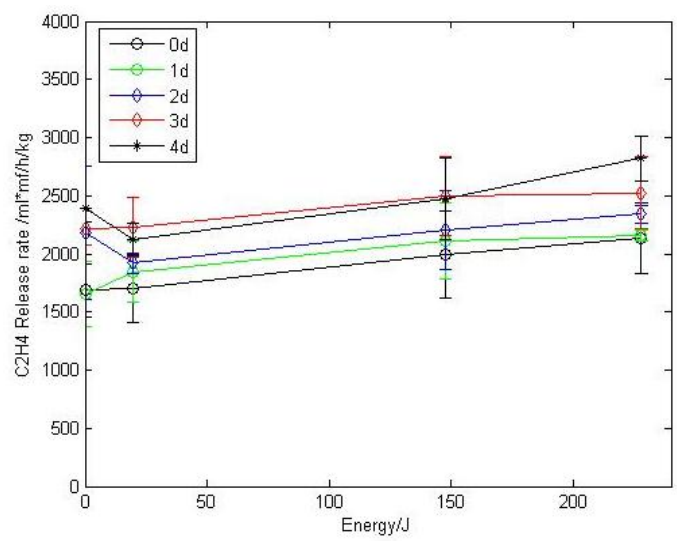

Fig. 4. Change relation of damage bananas first enduring mechanical energy and ethylene release rate. 
Fig. 5 showed the ethylene release rate of banana damaged by different loading forces in different storage days, it could be seen that with the increase of storage days, the ethylene release rates of banana damaged by different loading forces appeared the increase at the earlier stage, at the day 4, when the first loading forces were $20 \mathrm{~N}$ and $40 \mathrm{~N}$, the release rates of ethylene $\mathrm{C}_{2} \mathrm{H}_{4}$ began to drop. Except that the ethylene release rats in the day 1 and day 2 day had a significant fluctuations, ethylene $\mathrm{C} 2 \mathrm{H} 4$ release rate increased with the increase of initial loading force, while the ethylene release rate under the loading force of $60 \mathrm{~N}$ occurred the most in the whole storage process. To the damaged bananas, if its endurable mechanical energy was bigger, the transformation ratio of mechanical energy to chemical energy was greater, the power of biochemical enzymatic reaction in damaged banana was bigger, and the fluctuations of the ethylene release rates were larger. Thus promoted the increase of release rate of ethylene from its maturity substance, after reaching the peak value, it decreased for individual seriously aging, while the maturity differences existed in the individual, the fluctuations affected the trend and the process and banana quality. To the naturally matured bananas, its maturing and aging process were relatively slow, and ethylene release rate appeared the continuous increase.

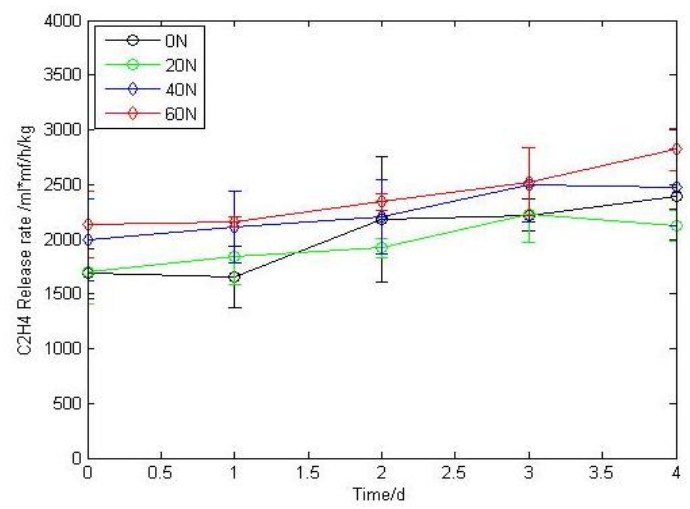

Fig. 5. The ethylene release rate of banana damaged by different loading forces in storage.

\section{Conclusions}

When Ripening bananas were loaded by force, there was a significant correlation between its energy transformation and the increment of maturity substances in would fruit. In the wound area, not only the mechanical energy transferring into the chemical energy in fruit, but also promoted the generation of its internal maturity substance $\mathrm{C}_{2} \mathrm{H}_{4}$, accelerated the maturity of banana, and caused the reduction of banana re-enduring mechanical energy and resistance to maximum damage stress, which is a important reason that the quality plant fruit declining day by day. There were the significant trends correlation of the quality evolution of banana damaged by load and the energy intensity of first loading force effect and the increasing of maturity substance concentration. The effect of high intensity loading mechanical energy and the enrichment of maturation substance and the maturing and aging of banana, the damaged and ruptured cells would increase and aggravate, the capacity of fruit resisting the germ invasion would significantly reduce, and the speed of fruit spoilage would increase, Therefore, based on banana quality protection, the energy intensity from the load should be lightened, the enrichment of maturity substance $\mathrm{C}_{2} \mathrm{H}_{4}$ should be reduced, and an energy and substance transformation model could be built, so as to prolong the physiological lifetime of banana in the process of 
storage. Overall, bananas are affected by many kinds of energy and substance transformation coupling during harvesting and processing, the comprehensive control of energy switching function is an important content of the system reducing the losses, the study involved nondestructive testing, storing and transporting etc., which still needs to be constantly improved and in-depth.

\section{Acknowledgment}

We thank the research team of Professor Weixin Chen, Guangdong Key Laboratory for Postharvest Science and Technology of Fruit and Vegetables, South China Agricultural University for their support in instrument measurements.

\section{References}

[1] W.J. Broughton, K.F. Wu. Storage conditions and ripening of two cultivars of banana. Scientia Horticulturae, Vol.10, no.1, January 1979, pp. 83-93.

[2] G.J. Strydom, C.S. Whitehead. The effect of ionizing radiation on ethylene sensitivity and postharvest ripening of banana fruit .Scientia Horticulture, Vol.41, no.4, February 1990, pp.293-304.

[3] F.K. Abd El-Wahab, M.A.M. Nawwar .Physiological and biochemical studies on chilling-injury of banana. Scientia Horticulture, Vol.7, no.4, December 1977, pp.373-376.

[4] J.O. Offem, O.O. Thomas. Chemical changes in relation to mode and degree of maturation of plantain (Musa paradisiaca) and banana (Musa sapientum) fruits. Food Research International, Vol.26, no.3, 1993, pp. 187193.

[5] A. Salvador, T. Sanz, S.M. Fiszman. Changes in color and texture and their relationship with eating quality during storage of two different dessert bananas. Postharvest Biology and Technology, Vol.43, no.3, March 2007, pp.319-325.

[6] Anurag Payasi, G. G. Sanwal. Pectate lyase activity during ripening of banana fruit. Phytochemistry, Vol. 63, no.3, June 2003, pp. 243-248.

[7] Rafaela González-Montelongo, M. Gloria Lobo, Mónica González. Antioxidant activity in banana peel extracts: Testing extraction conditions and related bioactive compounds. Food Chemistry, Vol.119, no.3, 1 April 2010, pp.1030-1039.

[8] Seemi Lohani, Prabodh K. Trivedi, Pravendra Nath. Changes in activities of cell wall hydrolases during ethylene-induced ripening in banana: effect of 1-MCP, ABA and IAA. Postharvest Biology and Technology, Vol.31, no.2, February 2004, pp.119-126.

[9] Zhengyong Yan, Maria J. Sousa-Gallagher, Fernanda A.R. Oliveira. Mathematical modeling of the kinetic of quality deterioration of intermediate moisture content banana during storage. Journal of Food Engineering, 2008, Vol.84, no.3, pp.359-367.

[10]P. Akkaravessapong, D.C. Joyce, D.W. Turner. The relative humidity at which bananas are stored or ripened does not influence their susceptibility to mechanical damage. Scientia Horticulture, Vol.52, no.3, November 1992, pp. 265-268.

[11]B. H. Hassan, A. M. Alhamdan, A. M. Elansar. Stress relaxation of dates at khalal and rutab stages of maturity. Journal of Food Engineering, Vol.66, no.4, February 2005, pp.439-445.

[12]J. B. Golding, D. Shearer, S. G. Wyllie, W. B. McGlasson. Application of 1-MCP and propylene to identify ethylene-dependent ripening processes in mature banana fruit. Postharvest Biology and Technology, Vol. 14, no. 1, September 1998, pp.87-98. 